\title{
Problems and perceived needs for medical ethics education of resident physicians in Alexandria teaching hospitals, Egypt
}

A.M. Mohamed, ${ }^{1}$ M.A. Ghanem ${ }^{2}$ and A.A. Kassem ${ }^{3}$

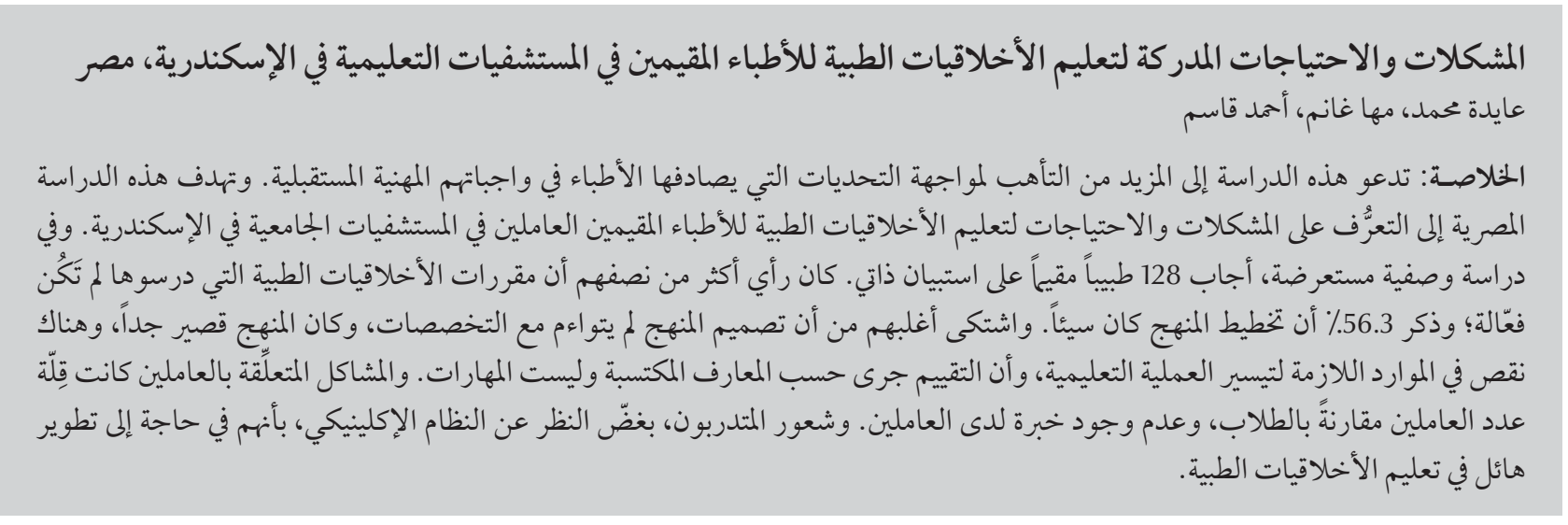

ABSTRACT There is a call for greater preparation for the ethical challenges encountered by physicians in their future professional duties. This study in Egypt aimed to reveal problems and perceived needs for medical ethics education of resident physicians working at University of Alexandria hospitals. In a descriptive, cross-sectional survey, 128 residents answered a self-administered questionnaire. More than half were of the opinion that their medical ethics course was ineffective; $56.3 \%$ mentioned poor curricular planning. The majority complained that the subject was not tailored to specialties, the course was too short, there was a shortage of resources to facilitate the educational process and that assessment was done for knowledge but not for skills. Problems related to staffing were low staff:student ratios and staff lack of experience. Trainees, regardless of clinical discipline, felt that there was a great need for improvement to their medical ethics education.

Problèmes et besoins perçus en matière de formation à l'éthique médicale des médecins internes des centres hospitaliers universitaires d'Alexandrie (Égypte)

RÉSUMÉ Certaines voix s'élèvent pour demander que les médecins soient mieux préparés aux difficultés éthiques qu'ils rencontreront dans leurs futures tâches professionnelles. Cette étude effectuée en Égypte auprès d'internes exerçant dans des hôpitaux de l'Université d'Alexandrie visait à révéler les problèmes posés par la formation à l'éthique médicale et les besoins perçus dans ce domaine. L'étude descriptive et transversale comprenait l'administration d'un autoquestionnaire auquel 128 internes ont répondu. Plus de la moitié d'entre eux estimaient que leur cours d'éthique médicale était inefficace, et ils étaient 56,3 \% à mentionner une mauvaise planification pédagogique. Une majorité d'entre eux se plaignait de l'absence d'adaptation aux différentes spécialités, de la brièveté du cours, du manque de ressources permettant de faciliter l'apprentissage et reprochait à l'évaluation d'être centrée sur les connaissances et non sur les compétences. Les problèmes ayant trait au personnel était le faible ratio personnel/étudiant et son manque d'expérience. Quelle que soit leur discipline clinique, les internes interrogés pensaient qu'une amélioration de leur formation à l'éthique médicale était grandement nécessaire.

${ }^{7}$ Department of Community Medicine; ${ }^{2}$ Department of Forensic Medicine and Toxicology; ${ }^{3}$ Department of Family Medicine, Faculty of Medicine, University of Alexandria, Alexandria, Egypt (Correspondence to A.M. Mohamed: aida_mohey@yahoo.com).

Received: 27/03/11; accepted: 24/07/11 


\section{Introduction}

Medical ethics in residency training is one of the crucial topics of continuous medical education debates ( 1 ). There is a call for more substantive preparation and training of physicians during their residency for ethical challenges encountered in their future professional duties (2).

Bioethics education has therefore been made a priority in medical training programmes because there is emerging evidence that ethics needs and preferences of medical residents evolve over time. Moreover, they face unique ethical conflicts that are related to their stage of training. Training in medical ethics helps physicians recognize ethical issues in patient care and resolve those issues wisely. Furthermore, such training has its maximum impact during the professionally formative years of residency $(1,3)$.

There is a need for strong promotion of continuous education in clinical ethics during residency and postgraduate training. In several studies, residents have expressed a preference for clinical ethics education to prepare them for ethical issues and dilemmas encountered in their practice $(1,4)$.

Over the past three decades, data gathered suggesting there are gender differences in the approach to health care ethics decision-making. Women residents perceived a greater need for ethics training and education. They valued ethics more and suggested more educational methods than did men $(5,6)$.

While ethics training has become a core component of medical residents' education, curricula have been developed without consulting residents about their needs for ethics instruction. There have also been calls to reinforce the need for accessible and easy-to-remember new approaches and methods to ethical and professional decision-making (7).

Understanding the perceptions of physician residents about ethics education and training will contribute to building effective ethics education directed at practical real-world dilemmas that in turn may support the development of good physicians. Academic disciplines which are responsible for teaching medical ethics should therefore pay greater attention to these topics in graduate medical curricula.

To our knowledge, there has been no systematic study in Egypt to investigate the views of residents in teaching hospitals on the need for practical ethics training. Moreover, little is known about the educational needs of practising physicians or their competencies in medical ethics in this country. For this reason, a survey was conducted to reveal problems in medical ethics education from the point of view of residents in University of Alexandria hospitals and to explore their perceived needs.

\section{Methods}

\section{Setting and sample}

A descriptive cross-sectional survey was conducted at the 3 university hospitals of Alexandria from August 2009 to September 2010. All physician residents of the faculty of medicine at University of Alexandria, working in 16 clinical departments, were invited to participate in this survey $(n=255$, according to the hospital information system, 2008).

\section{Data collection}

An anonymous self-administered questionnaire was developed. It covered the demographic characteristics of residents (sex, occupational category and postgraduate year) and residents views about medical ethics education and perceived needs for training. These were presented as 24 statements related to problems in medical ethics education in 4 domains: planning ( 8 items), teaching (3 items) assessment (3 items) and staff (11 items). The items were scored as 1 (agree) and 0 (disagree). Residents were also requested to suggest methods by which any unsuccessful aspects of the training could be improved.
Official approval for implementation of the study was obtained from the director of the university hospitals. A pilot study was conducted on a random subset of residents $(n=30)$ prior starting the fieldwork in order to obtain information that would improve the research plan and facilitate the execution of the study and to test the data collection tools regarding the content, phrasing and order of items. The main obstacle encountered was the poor cooperation of residents in returning the questionnaire. This was due to high workload and shift work patterns. The response rate was $50.2 \%$ and did not differ significantly by department of affiliation.

The ethics committee of the faculty of medicine approved the study. Questionnaires were distributed by the investigator herself with a covering letter indicating the purpose of the study, confidentiality procedures and faculty review approval. Informed consent was taken from residents before starting data collection, after a full explanation of the purpose and aims of the study. Data about residents' names, responses and views remained undisclosed by the researcher. After data analysis and final report writing all datasheets were shredded and disposed.

\section{Data processing and analysis}

After data collection, the raw data was coded and scored and a coding instruction manual was prepared. Data were fed to the computer and statistical analysis was performed using SPSS, version 18.0. The significance of the results was judged at the 5\% level of significance.

\section{Results}

\section{Respondents' characteristics}

Of the 128 residents who responded to the questionnaire, $50.8 \%$ were males and $49.2 \%$ females. About one-quarter (24.2\%) were working as internal medicine residents and $15.6 \%$ were specializing in family medicine; a minority 
were in the departments of paediatrics (6.3\%) and psychiatry (3.1\%). More than half of respondents (50.8\%) were residents in other departments (dermatology, emergency medicine, obstetrics and gynaecology, surgery, radiology and anaesthesiology). Out of the total respondents, $13.2 \%$ were 1 st year Masters students, $34.4 \%$ were 2nd year, $28.1 \%$ were 3 rd year and only $24.2 \%$ were in the 4 th year. No significant sex differences were observed among residents according to clinical department $(P=0.528)$ or postgraduate year $(P=0.724)$.

All residents received ethics education during their postgraduate years, most commonly in the 2 nd year (34.4\%). Less than half of residents (47.7\%) were of the opinion that the courses were effective, while $52.3 \%$ believed they were ineffective.

\section{Planning problems}

\section{Poor planning of curriculum}

Of the residents who responded, 56.3\% complained of poor planning of the curriculum. Significant sex differences were observed $(P=0.042)$, with more males $(61.5 \%)$ than females $(50.8 \%)$ agreed that poor planning was a problem (Table 1). The majority of residents affiliated to family medicine (80.0\%) and psychiatry $(75.0 \%)$ stated poor planning compared with $62.5 \%$ of those attached to paediatrics and $35.5 \%$ of those in the internal medicine department (Table 2). Over half of residents (56.9\%) attached to other departments mentioned poor planning. These differences were statistically significant $(P$ $=0.007)$. The majority of 1 st year residents ( $82.4 \%$ ) believed poor curriculum planning was a problem compared with $54.5 \%$ of 2 nd year residents, $50.5 \%$ of $3 \mathrm{rd}$ year residents and $51.6 \%$ of 4 th year residents $(P=0.029)$ (Table 3$)$.

\section{Course not tailored to specialties}

The majority of residents (85.2\%) complained that the subject of medical ethics was taught in a generic way and was not tailored according to the particular needs of each specialty. No significant differences were observed by sex $(P=0.893)$, specialty $(P=0.495)$ or postgraduate year $(P=0.742)$ (Tables $1-3)$.

\section{Poor timing of course}

Less than three-quarters of residents (72.7\%) felt that the timing of the course was inappropriate, i.e. was delivered either too late or too early within the schedule of the residency education programme. No significant differences were observed when sex $(P=0.782)$, department of affiliation $(P=0.059)$

\begin{tabular}{|c|c|c|c|c|c|c|c|c|}
\hline \multirow[t]{2}{*}{ Problem domain/statement ${ }^{a}$} & \multicolumn{2}{|c|}{$\begin{array}{l}\text { Males }^{\mathrm{b}} \\
(\boldsymbol{n}=65)\end{array}$} & \multicolumn{2}{|c|}{$\begin{array}{c}\text { Females }^{b} \\
\quad(n=63)\end{array}$} & \multicolumn{2}{|c|}{ Total $^{b}$} & \multirow[t]{2}{*}{$x^{2}$} & \multirow[t]{2}{*}{$P$-value } \\
\hline & No. & $\%$ & No. & $\%$ & No. & $\%$ & & \\
\hline \multicolumn{9}{|l|}{ Planning } \\
\hline Poor planning of curriculum & 40 & 61.5 & 32 & 50.8 & 72 & 56.3 & 5.438 & 0.042 \\
\hline Course not tailored to specialty & 55 & 84.6 & 54 & 85.7 & 109 & 85.2 & 0.142 & 0.893 \\
\hline Poor timing of course & 48 & 73.8 & 45 & 71.4 & 93 & 72.7 & 0.296 & 0.782 \\
\hline Course too short & 50 & 76.9 & 47 & 74.6 & 97 & 75.8 & 0.625 & 0.617 \\
\hline Course too theoretical & 44 & 67.7 & 53 & 84.1 & 97 & 75.8 & 6.318 & 0.016 \\
\hline Lack of teaching resources & 55 & 84.6 & 53 & 84.1 & 108 & 84.4 & 0.016 & 0.902 \\
\hline Overcrowded teaching sessions & 58 & 89.2 & 57 & 90.5 & 115 & 89.8 & 0.295 & 0.836 \\
\hline \multicolumn{9}{|l|}{ Teaching methods } \\
\hline Over-reliance on lectures & 60 & 92.3 & 60 & 95.2 & 120 & 93.8 & 0.293 & 0.845 \\
\hline Lack of practical sessions & 58 & 89.2 & 58 & 92.1 & 116 & 90.6 & 0.373 & 0.647 \\
\hline No teaching by simulation & 53 & 81.5 & 55 & 87.3 & 108 & 84.4 & 0.491 & 0.527 \\
\hline \multicolumn{9}{|l|}{ Assessment } \\
\hline Assessed knowledge only & 50 & 76.9 & 60 & 95.2 & 110 & 85.9 & 5.813 & 0.017 \\
\hline No assessment at clinical rounds & 59 & 90.8 & 58 & 92.1 & 117 & 91.4 & 0.198 & 0.893 \\
\hline Absence of feedback & 41 & 63.1 & 58 & 92.1 & 99 & 73.3 & 7.953 & 0.008 \\
\hline \multicolumn{9}{|l|}{ Staff } \\
\hline Staff to student ratio low & 45 & 69.2 & 41 & 65.1 & 86 & 67.2 & 0.492 & 0.501 \\
\hline Staff inexperienced in medical ethics & 14 & 21.5 & 11 & 17.5 & 25 & 19.5 & 2.947 & 0.197 \\
\hline Staff too busy & 44 & 67.7 & 34 & 54.0 & 78 & 60.9 & 5.082 & 0.028 \\
\hline Staff lack motivation & 43 & 66.2 & 37 & 58.7 & 80 & 62.5 & 3.419 & 0.059 \\
\hline
\end{tabular}

${ }^{a}$ Statements are mutually exclusive; ${ }^{b}$ Number and percentage of residents who agreed that this was a problem. 


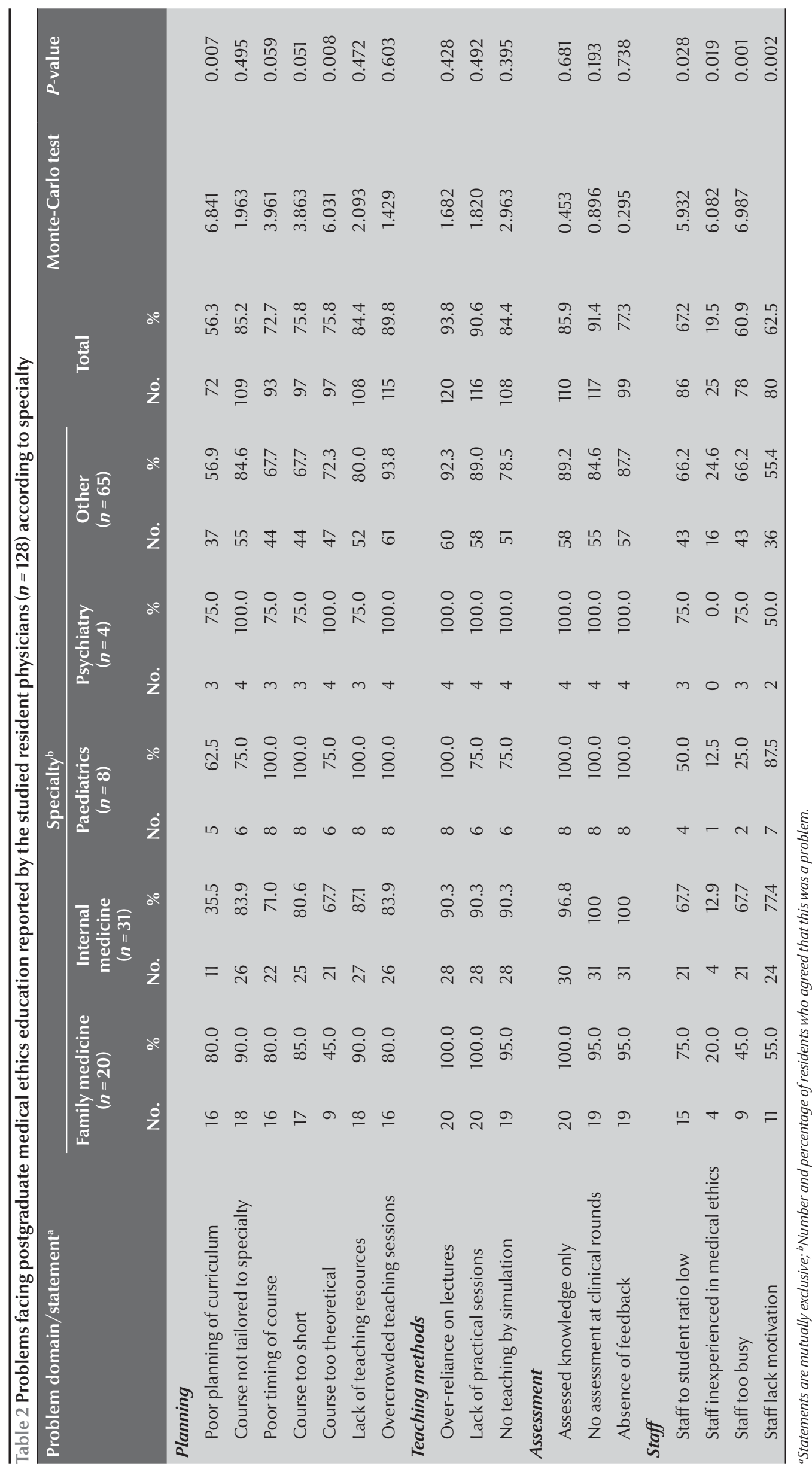


or postgraduate year $(P=0.684)$ were considered (Tables 1-3).

\section{Course too short}

Just over three-quarters of residents (75.8\%) felt that the course given was too short. No significant differences were observed when sex $(P=0.617)$ or department of affiliation $(P=0.051)$ were considered (Tables 1 and 2). The majority of 1 st year (94.1\%) and 2nd year residents $(81.8 \%)$ commented about the shortness of the course compared with $69.4 \%$ of 3 rd year and $64.5 \%$ of 4 th year residents $(P=0.017)$ (Table 3$)$.

\section{Course too theoretical}

More than three-quarters of residents (75.8\%) felt that the course was too theoretical. Significantly more females (84.1\%) than male residents (67.7\%) stated this problem $(P=0.016)$ (Table 1). All residents affiliated to the psychiatry department stated this problem compared with $75.0 \%$ attached to paediatrics, $67.7 \%$ of residents specializing in internal medicine and $72.3 \%$ of those working in other departments. Residents specializing in family medicine were the least likely to mention this problem $(45.0 \%)(P=0.008)$ (Table 2$)$.

\section{Lack of teaching resources}

The majority of residents (84.4\%) stated that shortage of resources to facilitate the educational process (e.g. videos showing different ethical dilemmas problem). No significant differences were observed in the responses of residents by sex $(P=0.902)$, department of affiliation $(P=0.472)$ or postgraduate year $(P=0.294)$ (Tables $1-3)$.

\section{Overcrowded teaching sessions}

The majority of residents (89.8\%) complained about the large number of postgraduate students. No significant differences were observed in the responses of residents when sex $(P=$ 0.836), department of affiliation $(P=$ $0.603)$ or postgraduate year $(P=0.083)$ were considered (Tables 1-3).

\section{Teaching methods}

\section{Over-reliance on lectures}

The majority of residents (93.8\%) criticized the dependence of staff on lectures as a mean of teaching. No significant differences were observed in responses of residents when sex $(P=0.845)$ or department of affiliation $(P=0.428)$ or year of graduation $(P=0.363)$ were considered (Tables 1-3).

\begin{tabular}{|c|c|c|c|c|c|c|c|c|c|c|c|c|}
\hline \multirow[t]{3}{*}{ Problem domain/statement ${ }^{a}$} & \multicolumn{8}{|c|}{ Postgraduate year ${ }^{b}$} & & & \multirow[t]{3}{*}{$x^{2}$} & \multirow[t]{3}{*}{$P$-value } \\
\hline & \multicolumn{2}{|c|}{$\begin{array}{l}\text { 1st year } \\
(n=17)\end{array}$} & \multicolumn{2}{|c|}{$\begin{array}{c}\text { 2nd year } \\
(n=44\end{array}$} & \multicolumn{2}{|c|}{$\begin{array}{l}\text { 3rd year } \\
(n=36)\end{array}$} & \multicolumn{2}{|c|}{$\begin{array}{l}\text { 4th year } \\
(n=31)\end{array}$} & \multicolumn{2}{|c|}{ Total } & & \\
\hline & No. & $\%$ & No. & $\%$ & No. & $\%$ & No. & $\%$ & No. & $\%$ & & \\
\hline \multicolumn{13}{|l|}{ Planning } \\
\hline Poor planning of curriculum & 14 & 82.4 & 24 & 54.5 & 18 & 50.5 & 16 & 51.6 & 72 & 56.3 & 5.923 & 0.029 \\
\hline Course not tailored to specialty & 15 & 88.2 & 37 & 84.1 & 31 & 86.1 & 26 & 83.9 & 109 & 85.2 & 0.284 & 0.742 \\
\hline Poor timing of course & 13 & 76.5 & 33 & 75.0 & 25 & 69.4 & 22 & 71.0 & 93 & 72.7 & 0.263 & 0.684 \\
\hline Course too short & 16 & 94.1 & 36 & 81.8 & 25 & 69.4 & 20 & 64.5 & 97 & 75.8 & 5.024 & 0.017 \\
\hline Course too theoretical & 12 & 70.6 & 28 & 63.6 & 27 & 75.0 & 20 & 64.5 & 97 & 75.8 & 0.495 & 0.641 \\
\hline Lack of teaching resources & 17 & 100.0 & 38 & 86.4 & 27 & 7.0 & 26 & 83.9 & 108 & 84.4 & 0.752 & 0.294 \\
\hline Overcrowded teaching sessions & 16 & 94.1 & 40 & 90.9 & 34 & 94.4 & 25 & 80.6 & 115 & 89.8 & 1.834 & 0.083 \\
\hline \multicolumn{13}{|l|}{ Teaching methods } \\
\hline Over-reliance on lectures & 16 & 94.1 & 42 & 95.5 & 36 & 100.0 & 26 & 83.9 & 120 & 93.8 & 0.825 & 0.363 \\
\hline Lack of practical sessions & 17 & 100.0 & 38 & 86.4 & 34 & 94.4 & 27 & 87.1 & 116 & 90.6 & 1.023 & 0.094 \\
\hline No teaching by simulation & 15 & 88.2 & 36 & 81.8 & 32 & 88.9 & 25 & 80.6 & 108 & 84.4 & 0.934 & 0.584 \\
\hline \multicolumn{13}{|l|}{ Assessment } \\
\hline Assessed knowledge only & 16 & 94.1 & 43 & 97.7 & 34 & 94.4 & 27 & 87.1 & 110 & 85.9 & 0.592 & 0.503 \\
\hline No assessment at clinical rounds & 15 & 88.2 & 43 & 97.7 & 34 & 94.4 & 25 & 80.6 & 117 & 91.4 & 2.853 & 0.062 \\
\hline Absence of feedback & 15 & 88.2 & 43 & 97.7 & 33 & 91.7 & 28 & 90.3 & 99 & 77.3 & 0.035 & 0.746 \\
\hline \multicolumn{13}{|l|}{ Staff } \\
\hline Staff to student ratio low & 14 & 82.4 & 29 & 65.9 & 23 & 63.9 & 20 & 64.5 & 86 & 67.2 & 3.856 & 0.062 \\
\hline $\begin{array}{l}\text { Staff inexperienced in medical } \\
\text { ethics }\end{array}$ & 2 & 11.8 & 10 & 22.7 & 7 & 19.4 & 6 & 19.4 & 25 & 19.5 & 2.853 & 0.092 \\
\hline Staff too busy & 9 & 52.9 & 27 & 61.4 & 26 & 72.2 & 16 & 51.6 & 78 & 60.9 & 5.041 & 0.038 \\
\hline Staff lack motivation & 9 & 52.9 & 30 & 68.2 & 22 & 61.1 & 19 & 61.3 & 80 & 62.5 & 0.963 & 0.138 \\
\hline
\end{tabular}

${ }^{a}$ Statements are mutually exclusive; ${ }^{b}$ Number and percentage of residents who agreed about the problem. 


\section{Lack of practical sessions}

The majority of residents (90.6\%) stated that the teaching methods did not include applied practical sessions. No significant differences were observed by sex $(P=0.647)$ or department of affiliation $(P=0.492)$ or postgraduate year $(P=0.094)$ (Tables $1-3)$.

\section{No teaching by simulation}

The majority of residents (84.4\%) stated that the teaching methods did not include role play or videos. No significant differences were observed in the responses of residents when sex $(P$ $=0.527)$, department of affiliation $(P=$ $0.395)$ or postgraduate year $(P=0.584)$ were considered (Tables 1-3).

\section{Assessment}

\section{Assessed knowledge only}

The majority of residents (85.9\%) stated that assessment was restricted only to knowledge gained rather than skills. This was stated by significantly more female residents (95.2\%) than male residents $(76.9 \%)(P=0.017)$ (Table 1). No significant differences were observed in the responses of residents when department of affiliation $(P=0.681)$ or postgraduate year $(P$ $=0.503$ ) were considered (Tables 2 and 3 ).

\section{No assessment at clinical rounds}

The majority of residents (91.4\%) stated that no assessment was carried out during clinical rounds. No significant differences were observed in the responses of residents when sex $(P=$ $0.893)$, department of affiliation $(P=$ $0.193)$ or postgraduate year $(P=0.062)$ were considered (Tables 1-3).

\section{Absence offeedback}

Almost three-quarters of residents (73.3\%) complained that postgraduates did not receive any feedback about their performance as regards medical ethics after completion of courses in their departments. This was mentioned by significantly more female (92.1\%) than male residents (63.1\%)
$(P=0.008)$ (Table 1$)$. No significant differences were observed in the responses of residents when department of affiliation $(P=0.738)$ or postgraduate year $(P=0.746)$ were considered (Table 2 and 3 ).

\section{Staff}

\section{Staff to student ratio low}

More than two-thirds of residents (67.2\%) stated that the staff to student ratio was low. No significant differences were observed in the responses of residents according to their sex $(P=$ 0.501 ) (Table 1). Significant differences were observed when department of affiliation was considered $(P=0.028)$. Significantly more family medicine (75.0\%) and psychiatry department residents $(75.0 \%)$ mentioned the low staff to student ratio as a problem compared with internal medicine (67.7\%), paediatrics $(50.0 \%)$ and residents attached to other departments (66.2\%) (Table 2). No significant differences in the responses of residents were observed by year of graduation $(P=$ 0.062) (Table 3).

\section{Staff inexperienced in medical ethics}

Another problem, according to $19.5 \%$ of residents, was that teaching staff lacked expertise in medical ethics. No significant differences were observed in the responses of residents when sex $(P=0.197)$ or postgraduate year $(P=$ 0.092 ) were considered (Tables 1 and $2)$. Significantly more residents affiliated to other departments (24.6\%) and those specializing in family medicine (20.0\%) were unsatisfied with the lack of expertise of staff in medical ethics compared with those attached to internal medicine $(12.9 \%)$ or to psychiatry (12.5\%) $(P=0.019)$ (Table 3).

\section{Staff too busy}

Three-fifths of residents (60.9\%) stated that teaching staff were too busy. Significant sex differences were observed $(P=0.028)$ with more males $(67.7 \%)$ than females (54.0\%) believing it was a problem (Table 1). Three-quarters of residents attached to psychiatry (75.0\%), $67.7 \%$ of those attached to internal medicine department and $66.2 \%$ of those attached to other departments stated that staff were too busy compared with $45.0 \%$ of those affiliated to family medicine and $25.0 \%$ of paediatrics departments. The differences observed were statistically significant $(P=0.001)$ (Table 2). Less than three-quarters of $3 \mathrm{rd}$ year residents (72.2\%) found it a problem compared with $61.4 \%$ of 2 nd year residents, $52.9 \%$ of 1 st year residents and $51.6 \%$ of 4 th year residents. The differences observed were statistically significant $(P=0.038)$ (Table 3).

\section{Staff lack motivation}

Less than two-thirds (62.5\%) of residents stated that staff were not motivated and lacked the positive attitudes for teaching process. No significant differences were observed in the responses of residents when sex $(P=0.059)$ or postgraduate year $(P=0.138)$ were considered (Tables 1 and 2). Significant differences were observed when the department of affiliation was considered. $(P=0.002)$ (Table 2). Paediatrics (87.5) and internal medicine residents (77.4\%) were more likely to state this compared with $55 \%$ who specialized in family medicine and those affiliated to other departments (55.4\%).

\section{Educational needs}

Regardless of level of training or clinical discipline, residents felt that there was a great need for improvement in postgraduate education in medical ethics. Over three-quarters of residents felt that there was a need for faculty staff development through training (76.5\%) and increasing the number of those who taught ethics (75.5\%). The majority of residents $(85.9 \%)$ recommended that the teaching of medical ethics should be fully integrated horizontally with the clinical courses and $78.9 \%$ of them felt that it should be linked to postgraduate education. Just less than two-thirds 
(64.8\%) recommended that the subject should be taught throughout the medical education course.

The majority of residents recommended that teaching of medical ethics should be more practical (92.2\%), with proper selection of effective teaching methods (91.4\%). Figure 1 illustrates the teaching methods recommended by respondents. Nearly all residents recommended case-based learning (94.5\%) and clinical attachments in ethics education (93.8\%). More than four-fifths ( $85.9 \%)$ recommended a combination of formal large and small group lectures or problem-based learning methods (85.2\%). Other methods mentioned were project work (73.4\%), small group teaching by expert staff (64.8\%) and seminars (64.1\%). Less than three-quarters of residents (71.9\%) felt that assessment should be carried out by clinical staff in their departments.

Women expressed slightly greater need for attention to ethics education than did men $(P<0.05)$, with the greatest difference for the issues of teaching and assessment of medical ethics being fully integrated horizontally with the clinical courses and proper selection of effective teaching methods (data not shown).

\section{Discussion}

All the studied residents felt that there was a great need for improvement of the postgraduate medical education in ethics. Their preference for integrating ethics throughout their medical education is particularly interesting. Several benefits could be derived from diverse and continuing exposure to the moral dimensions of medical care. It perpetuates the humanitarian tradition within medicine. Also, faculty staff can provide role models, especially at rounds, of the relevance and importance of moral practice to good medical care. Furthermore, courses and rounds together provide an opportunity for students to bridge ethical theory and moral decision-making in medical practice. Finally, it could assist students in defining their professional role, authority, responsibility and identity $\left({ }^{8}\right)$

Issues reported by the residents related to problems of curriculum planning, teaching methods, and staff and assessment methods. As regards curriculum planning, more than half of the residents surveyed (56.3\%) complained of poor planning of the curriculum. Surveys of medical ethics education at medical schools in the United States (US) and Canada provide a useful comparison with this study $(9,10)$. Items of similarity with our findings were inappropriate timing of the ethics component in the curriculum, overemphasis on theoretical elements and shortness of the course. Areas of difference were poor planning of the curriculum and shortage of resources. However, those surveys did not identify a lack of coordination between preclinical and clinical ethics training, perhaps because of the greater integration in US and Canadian medical schools. Concerning problems

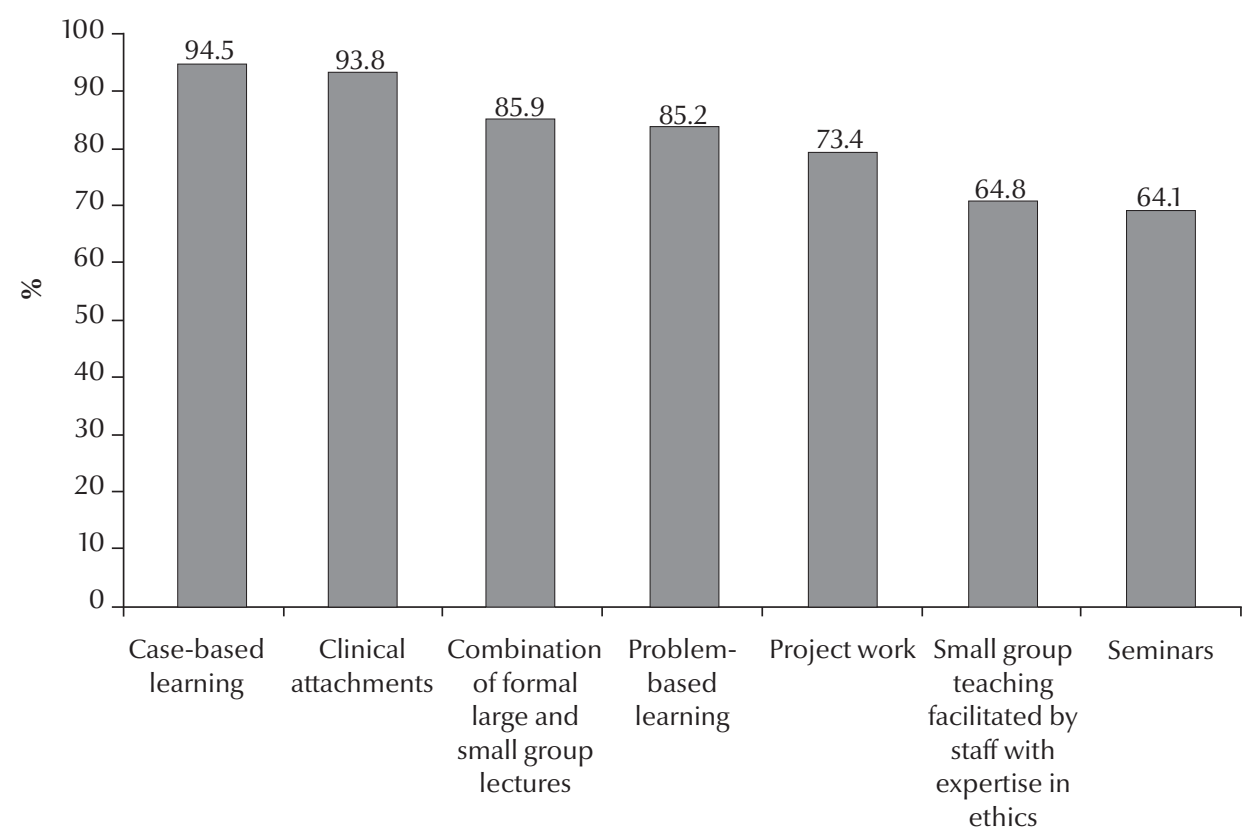

Figure 1 Distribution of the studied resident physicians $(n=128)$ by their recommended teaching methods for postgraduate ethics education (categories are mutually exclusive) 
related to teaching methods, most residents in our study criticized the dependence of staff on lectures as a mean of teaching. They also reported that teaching the methods did not include any applied practical sessions. The residents recommended that teaching of medical ethics should be more practical and use effective teaching methods. Nearly all residents would prefer case-based learning and attaching ethics education to clinical study which is in agreement with Levitt et al (11).

Small group teaching is an effective strategy for medical ethics education, being greater than traditional lectures in developing moral reasoning skills and normative identification with the future profession (12-14). Our study showed that small group clinical-based teaching was widely accepted as the best approach for ethics teaching by the residents. However, small group teaching usually requires more staff with the relevant expertise (12).

Concerning staffing, significantly more family medicine residents and psychiatry residents mentioned the low staff to student ratio as a problem. Other studies also reported a core group of ethics teachers within the medical school, with a very few individuals often responsible for ethics learning, the coordination of ethics teaching and much of the delivery itself (15-17).

A single identified person to take responsibility for ethics teaching in medical schools is desirable and acknowledged by Pond (18). However, the fact that an individual is central to all activities within the ethics curriculum raises questions about succession planning. Several recommendations were provided by our residents to improve staff problems in medical ethics education. A need for staff development through training and increasing the number of those who teach ethics were requested by the majority of residents.

As in a previous study (12), women residents in the present study perceived greater curricular needs for many items of ethics education than did men. The reasons behind this gender effect are unclear and warrant further research. Because women represented $49.2 \%$ of all residents surveyed, and as many as $74 \%$ of residents in certain specialty areas, it is important to determine the pattern of and reasons for these differing views $(19,20)$.

Women are an increasingly important stakeholder group in academic medical settings, and in the present study - as with others - they had greater unmet needs for ethics training $(21,22)$. In comparison to men, several researches have shown that women take the action that has best consequences and put emphasis on relationships, values, compassion, and an overall "ethics of care" in clinical ethics decisionmaking. However, men often express narrower principles and follow the rules over consideration of consequences $(12,23)$.

As with other studies (2,24-26), we found that residents majoring in psychiatry, internal medicine, paediatrics and family medicine more strongly endorsed curricular needs related to ethical issues. Future work will continue to help clarify whether there are in fact different ethics education needs of residents in diverse fields of medicine.

Our study also showed that senior residents at later stages of training perceived a greater need for attention to ethics in the curriculum. This may be because senior residents are more aware of their unmet need for ethics training than the junior ones. Moreover, by the time they become senior residents physicians may have faced more complex clinical and ethical issues and need to deal with these effectively.

In conclusion, this survey, the first of its kind in University of Alexandria teaching hospitals, raises some important issues for ethics education. It suggests there is a need to include novel and important ethics domains in the training curricula across medical school and diverse residency programmes. Faculty staff members therefore need to review the curricula in a systematic and efficient way. Moreover, they have to ensure that certain topics receive particular emphasis in some specialty areas and that the interests of women physicians accommodated.

Some limitations to the study should be noted. The survey relied on self-reporting about problems of ethics education. It was conducted at a single institution (including only residents of teaching hospitals); this limits the generalization of the results to other settings. Also, the low response rate for the questionnaire (50.2\%) suggests there was a sampling bias. In addition, due to small the number of residents in certain specialties, the study did not have sufficient power to permit more detailed analyses. For example, psychiatry residents endorsed the greatest need for additional ethics education on specific topics in comparison with their colleagues. The actual explanation is unknown and warrants further investigation. It could be due to higher ethical sensitivity related to this specialty, greater perception of ethical complexity in mental health work, or less training in psychiatric ethics.

\section{References}

1. Civaner M, Sarikaya O, Balcioğlu H. Uzmanlik eğitiminde tip etiği [Medical ethics in residency training]. Anadolu Kardiyol Derg. 2009 Apr;9(2):132-8 [In Turkish]. PMID:19357056
2. Roberts LW, Geppert CMA, Warner TD, Green Hammond KA, Lamberton LP. Bioethics principles, informed consent, and ethical care for special populations: curricular needs 
expressed by men and women physicians-in-training. Psychosomatics. 2005 Sep-Oct;46(5):440-50. PMID:16145189

3. Hundert EM, Hafferty F, Christakis D. Characteristics of the informal curriculum and trainees' ethical choices. Acad Med. 1996 Jun;71(6):624-42. PMID:9125919

4. Roberts LW, McCarty T, Lyketsos C, Hardee JT, Jacobson J, Walker R, et al. What and how psychiatry residents at ten training programs wish to learn about ethics. Acad Psychiatry. 1996 Sep;20(3):131-43. PMID:24442690

5. Price J, Price D, Williams G, Hoffenberg R. Changes in medical student attitudes as they progress through a medical course. J Med Ethics. 1998 Apr;24(2):110-7. PMID:9602998

6. Elzubeir MA, Rizk DE. Exploring perceptions and attitudes of senior medical students and interns to academic integrity. Med Educ. 2003 Jul;37(7):589-96. PMID:12834415

7. Roberts LW, WarnerTD, Hammond KA, Geppert CM, Heinrich T. Becoming a good doctor: perceived need for ethics training focused on practical and professional development topics. Acad Psychiatry. 2005 Jul-Aug;29(3):301-9. PMID:16141129

8. Shelp EE, Russell ML, Grose NP. Students' attitudes to ethics in the medical school curriculum. J Med Ethics. 1981 Jun;7(2):703. PMID:7252992

9. Lehmann LS, Kasoff WS, Koch P, Federman DD. A survey of medical ethics education at U.S. and Canadian medical schools. Acad Med. 2004 Jul;79(7):682-9. PMID:15234922

10. Mattick K, Bligh J. Teaching and assessing medical ethics: where are we now? J Med Ethics. 2006 Mar;32(3):181-5. PMID:16507668

11. Levitt C, Freedman B, Kaczorowski J, Adler P, Wilson R. Developing an ethics curriculum for a family practice residency. Acad Med. 1994 Nov;69(11):907-14. PMID:7945693

12. Self DJ, Wolinsky FD, Baldwin DC Jr. The effect of teaching medical ethics on medical students' moral reasoning. Acad Med. 1989 Dec;64(12):755-9. PMID:2590358

13. Goldie J, Schwartz L, McConnachie A, Morrison J. Impact of a new course on students' potential behaviour on encountering ethical dilemmas. Med Educ. 2001 Mar;35(3):295-302. PMID:11260454
14. Mattick K, Bligh J. Teaching and assessing medical ethics: where are we now? J Med Ethics. 2006 Mar;32(3):181-5. PMID:16507668

15. Lakhan SE, Hamlat E, McNamee T, Laird C. Time for a unified approach to medical ethics. Philos Ethics Humanit Med. 2009 09 08;4:13. PMID:19737406

16. Goldie J. Review of ethics curricula in undergraduate medical education. Med Educ. 2000 Feb;34(2):108-19.PMID:10652063

17. Shelp EE, Russell ML, Grose NP. Students' attitudes to ethics in the medical school curriculum. J Med Ethics. 1981 Jun;7(2):703. PMID:7252992

18. The Pond report: report of a working party on the teaching of medical ethics. London: Institute of Medical Ethics; 1987.

19. Hojat M, Gonnella JS, Xu G. Gender comparisons of young physicians' perceptions of their medical education, professional life, and practice: a follow-up study of Jefferson Medical College graduates. Acad Med. 1995 Apr;70(4):305-12. PMID:7718063

20. Wertz DC. Is there a "women's ethic" in genetics: a 37-nation survey of providers. J Am Med Womens Assoc. 1997 Winter;52(1):33-8. PMID:9033171

21. More women than men seek entry to US medical schools. Medical News Today. 2003; 27 November.

22. Shrier DK. A celebration of women in US medicine. Lancet. 2004;363:253.

23. Clark V, Yamagata H, Chapman W. Women in U.S. academic medicine statistics: 2002-2003. Washington DC. Association of American Medical Colleges; 2003.

24. Coverdale JH, Bayer T, Isbell P, Moffic S. Are we teaching psychiatrists to be ethical? Acad Psychiatry. 1992 Dec;16(4):199205. PMID:24435428

25. Jacobson JA, Tolle SW, Stocking C, Siegler M. Internal medicine residents' preferences regarding medical ethics education. Acad Med. 1989 Dec;64(12):760-4. PMID:2590359

26. Morenz B, Sales B. Complexity of ethical decision making in psychiatry. Ethics Behav. 1997;7(1):1-14. PMID:11654854 